\title{
A Brief Review of Microgenetic Method in Second Language Acquisition Research
}

\author{
Lu Chen ${ }^{1, *}$ \\ ${ }^{1}$ School of Chinese Language and Literature, University of International Business and Economics, Beijing 100029, \\ China \\ *Corresponding author. Email: luchen_95cl@163.com.
}

\begin{abstract}
Microgenetic method is a specific method emerging in cognitive psychology. Over the past two decades, an increasing number of cognitive psychologists adopted this method to investigate the trajectory and mechanism of cognitive development with a focus on the variability within a specific group or subject. This paper provided a brief overview of microgenetic method and listed its potential advantages and disadvantages in the context of Second Language Acquisition (SLA). Meanwhile, systematical evaluation of the current empirical research indicates that although microgenetic method has good adaptability in SLA research, especially for studying sociocultural approaches and frequency effects, research gap still exists which worth further investigation.
\end{abstract}

Keywords: microgenetic method; second language acquisition; empirical research; sociocultural theory;

frequency effect

\section{INTRODUCTION}

It has become a consensus that the process of Second Language Acquisition (SLA) is extremely complicated. This complexity not only exists in the language system, internal and external factors of learners, the circumstances surrounding learners, but also in the interaction between different systems. According to dynamic system theory (DST), language is a dynamic system and language acquisition is dynamic adaptedness full of progress, regress and stagnation; that change can be gradual and it can be sudden (Larsen-Freeman, 2006) [1]. Standard crosssectional and longitudinal researches typically study the second language development among learners at various ages or levels, but neglect the extensive occurrence of variability during and between stages of second language development, and cannot reflect the true second language performance.

Microgenetic method could be defined as a specific method for uncovering the trajectory and mechanism of cognitive development with a focus on variability within a specific group or a subject during a relatively short period of time, through dense observations, under in-depth quantitative and qualitative analysis. Microgenetic method is identified with three essential properties which distinguish it from conventional cross-sectional and longitudinal methods (Granott\&Parziale, 2002; Siegler, 2007) [2,3]: (a)an adequate observation period: The observation period can be tens of minutes, hours, days, weeks, or months. For example, the observation period in Siegler\&Crowley (1991) [4] was as long as 11 weeks, three times a week; and was 6 and a half hours in Schauble (1996) [5]; some were only 30 minutes (Bjorklun et al., 1992; Millr \& Aloise -Young, 1996) $[6,7]$. The ideal situation is a period from the beginning of a process of change until a relatively stable state, covering the whole process of the change.; (b) dense observation: The frequency of observation is highly relative to the rate and the period of change. Siegler and Crowley [4] used a hurricane hitting a city as an example to illustrate the frequency of observation. We can only estimate the damage caused by the hurricane by comparing two photos: one before the hurricane and one after the hurricane. But if you want to know the whole process, you need to make a film or at least take a series of photos at a high frequency. By intensive sampling, researchers can discover the key points of change, the trajectory and mechanism of change. (c) detailed analysis: Only a detailed analysis of the qualitative or quantitative changes of subjects, can distinguish different causes of change and in what condition change emerge. Take the microgenetic study of learning strategies as an example. If data analysis is limited to quantitative changes, it is impossible to explain some questions, such as why a subject gives up a given strategy after several successful attempts? Why a subject can use a strategy proficiently which has been abandoned after several failed attempts?

In this paper, I will provide a brief overview of microgenetic method and will point out its potential advantages and disadvantages. In the meantime, the current empirical researches based on this method in SLA were examined and evaluated systematically. 


\section{THEORETICAL DEVELOPMENT OF MICROGENETIC METHOD}

Both the name microgenetic and the idea of microgenetic designs were raised by psychologist Heinz Werner (Siegler, 2007) [3]. In the mid-1920s, he performed "genetic experiments" which aimed to describe the unfolding of successive representations that composed psychological events. Then, Werner (1940) [8] investigated how people can distinguish and represent 12 ascending, initially indiscriminable tones, after repeated presentations. It is believed that this rapid sequence of mental states parallels the much slower sequence of states in development with age, so the experiments were also labeled as "microgenetic" (Siegler, 2007) [3]. This method was later approved by many contemporaries, including Vygotsky (1978) [9] and adopted by researchers working in the area of developmental psychology, such as Piagetian, Vygotskyan.

Many microgenetic studies have indicated that the development of children's cognitive abilities is a process full of variability and change. For example, different subjects use different strategies; a subject uses different strategies on the same problem on two occasions close in time, and so on (Siegler, 1996) [10]. To capture such variability and changes, Siegler (1996, 2002) [10,11] proposed the overlapping waves theory which emphasizes the unevenness and variability in development. The development of children's cognitive abilities can be fast, slow or stagnant in different time periods, sometimes it moves forward and sometimes it moves backward. For example, the successful attempt of a strategy does not mean that it will be remembered and always effective, while a failed attempt of a certain strategy does not mean that it is completely abandoned in the future. Children may temporarily deviate from the goal to be able to approach it better in the future.

Microgenetic analysis, a new methodological approach for examining and analyzing the variability and change in learning progress, is a powerful support for Siegler's overlapping waves model (Siegler, 2000) [12]. Microgenetic method and the Siegler's overlapping waves theory have posed a powerful challenge to the existing cognitive development theories which generally focus on the typical and regular performance of a certain stage, but ignore the variability. Sicgler (2002) [11] used the ladderlike model to conceptualize Piaget's cognitive development theory (sensorimotor stage, preoperational stage, concrete operational stage and formal operational stage) and pointed out that this model only reflects the macro-trend of group development, but conceals the true situation of children's cognitive development which is full of variations within a group or an individual.

\section{ADVANTAGES AND DISADVANTAGES}

Miller and Coyle (1999) [13] summarized the four major advantages of microgenetic approach. First, this method can directly observe ongoing changes in the process. Current cross-sectional studies and some longitudinal studies of second language acquisition did provide valuable data on the characteristics of knowledge and skills acquired by SL learners at different levels, but they just focus on certain static points of development and the interval between them is too large, so these studies cannot provide description and explanation about how learner's second language abilities develop from one stage to another and infer the trajectory and mechanism of change in progress. In contrast, the high-frequency sampling and detailed data analysis required by microgenetic method are ideal ways to capture subtle changes. Subjects are usually asked to make repetitive attempts in trial-by-trial tests. Through intensive observation, this dynamic tracking method captures the most concentrated and rapid time period of changes, so as to provide description and explanation for changes that are taking place.

The second advantage is that the data yielded by microgenetic studies can be analyzed from different dimensions. Siegler (1995, 1998) [14,15] proposed five dimensions of change: path, rate, breadth, variability and sources of change. According to Siegler's theory, the path of change refers to the series of attempts made by the subject to master a specific concept or skill. The rate of change refers to how quickly a specific change can be used consistently once it begins to be used on a given task. Group data generally cannot reveal the true rate of change. The speed of change is often relatively slow seen from group data analysis, but in fact, it may be very rapid for different individuals or in different time periods. Breadth refers to the range of certain concepts or skills that subjects can apply, and variability refers to differences between individuals and differences within an individual learner in the change process. The sources of change refer to the causes which give rise to change. These five dimensions may vary with different tasks, different situations and different individuals. Second language acquisition is a dynamic and complex system, and in Siegler's framework, microgenetic method can explain the complexity of changes in SLA by identifying the most likely conditions and causes give rise to change.

The third advantage is that this method can help us identify variability that occurs in the changes within a group or a subject. Cross-sectional research and group data analysis only pay attention to the typical behaviors of learners with different levels of SL proficiency. For example, beginnerleveled ESL (English as a second language) learners can master how many high-frequency words, sentence structures and what kind of mistakes they usually make. However, group performance not only conceals the differences within a group, but also conceals the instability of individual behavior. On the contrary, the microgenetic approach considers all attempts made by different learners at different times.

The fourth advantage is that this method is of great applicability. It can be used to study different concepts and skills, such as the development of oral ability, pragmatic competence or the process of acquiring a given word family, a language structure. This method is also suitable 
for different theoretical schools of cognitive development, such as Piaget's theory, Neo-Piagetian theory, Vygotsky's theory, and information processing.

Although the microgenetic method has many advantages, it also has obvious limitations. First, this method only can be applied to small sample research. The size of sample is limited because researchers need to observe the subjects one by one, moment by moment and record in detail which is a time-consuming and labor-intensive task. Second, this method is only suitable for highly motivated subjects. Only do the subjects make active and serious attempts in multiple experiments from the beginning to the end, can the research yield valuable findings. Third, it is difficult to set an appropriate observation period which is very important for microgenetic studies. Some changes are too abstract and subtle to capture, so identifying when a change emerges and when it enters into a stable state is a challenge for researchers.

\section{EMPIRICAL RESEARCH OF MICROGENETIC METHOD IN SLA}

Although microgenetic method was widely adopted by developmental psychologists in their experiments for cognitive development, especially for children, the empirical research period of microgentic method in SLA is relatively short. Using second language acquisition and microgentic analysis as keywords, we only found 15 related publications on Wiley Online Library, PubMed and ResearchGate. The research field was mainly focused on English as a second language.

\subsection{Current Progress of International Research}

In recent years, this method has been applied to cognitive linguistics, sociolinguistics, and applied linguistics. Current microgenetic studies in SLA mainly concern trialby-trial assessment of changes. Most related articles use microgenetic analysis to capture ongoing changes in second language writing, speaking and pragmatic ability of L2 learners based on the sociocultural theory, created by Lev Vygotsky. The main idea of this theory is that people's behavior and mental ability are shaped by the ways they interact with people and the culture they live in.

Most microgenetic studies explore the effect of various strategies (e.g., peer interaction, languaging, concept-based instruction, dynamic assessment and gestures) on second language learning based on the zone of proximal development (ZPD) and scaffolding theory raised by Lev Vygotsky.

It is believed that peer collaboration is an effective pedagogical method to encourage students' collaborative production of spoken or written output in L2 classroom. Related studies explored the development of learner's SL writing and pragmatic abilities in peer interactions. In contrast to typical a ZPD pattern, which an expert helps a novice learner to achieve a higher level of regulation by supportive activities, De Guerrero \& Villamil (2002) [16] adopted microgenetic approach to analyze the peer collaboration of 2 novice learners (one as a writer and one as a reader) in the English as a Second Language (ESL) writing classroom. The purpose of the study was to observe how revision strategies emerge and develop in a joint revising task. In general, results showed that collaborative scaffolding such as peer revision is mutually beneficial to both the writer and the reader as they using various supportive behaviors to assist each other for achieving a higher level of regulation. Platt \& Brooks (2002) [17] examined data from two pairs of L2 learners (English native speakers) involving in jigsaw tasks, one pair using Swahili, the other Spanish. The purpose of the study is to identify task engagement in dialogic activities and the effect of task engagement on SL learning. The results showed that not only meaning, but also roles, voices, and the task procedures are established during the dialogic activity. Belz and Kinginger (2003) [18] examined the microgenetic development of second-person pronoun use by collecting data from a 3-year telecollaboration project between American learners of German and native speakers of German. The research showed that German-American telecollaborative partnership not only provides explicit help for learners, but also provides them with the opportunity to observe appropriate pronoun use. In this process, the learner's ability to use formal (T) and formal (V) appellations (du and Sie respectively in German) appropriately kept getting closer to the norm of native speakers. 'languaging', refers to the linguistic interaction between participants when they communicate with each other in a collaborative task. Knouzi et al. (2010) [19] investigated the languaging behaviour of two university students (high and low languagers) learning French as a second language and traced the development of their understanding of the French concept of voice. They found that languaging can served as a self-scaffolding tool for the higher languager to solve cognitive conflicts, mediate mental processes and construct meaning, while the lower languager always left conflicts unresolved for misinterpreting the task and function of languaging. DiCamilla and Antón (2012) [20] also analyzed interactions between the beginning and advanced learners of Spanish in a collaborative writing task to investigate the functions of L1 in a L2 classroom and the possibility of using L2 as an effective psychological tool as L1. Mirzaei and Eslami (2013) [21] investigated how L2 learners' engagement in collaborative writing tasks and their utilization of L2 metadiscourse help them achieve selfregulation and internalize new linguistic knowledge.

Collaboration with an expert or instructor who can provide various supportive activities is also an important way to mediate L2 learning process. Kim and Hall (2002) [22] investigated the effect of the interactive book reading program on Korean children's pragmatic competence development of English. In this program, children were treated as active participants and required to ask questions, make comments and engage in play activities. The findings suggested that participation in such reading programs 
promotes the development of L2 pragmatic competence, such as words, utterances, and talk management features. Concept-based instruction (CBI) is also a pedagogical approach based on sociocultural theory. The main idea of this approach is that instructors should provide learners with theoretical conceptual unit and materialize concepts by various mediation activities. van Compernolle (2011) [23] employed microgenetic method to analyze the development of an American learner's sociopragmatic knowledge related to French second-person pronouns 'TU and VOUS' in a CBI tutorial. Findings showed that mediating artifacts (e.g., written concept explanations and pedagogical diagrams) and collaborative activities (e.g., verbalized refection and self-directed speech) are all effective ways to mediate learners' L2 learning. Harun and Abdullah (2017) [24] focused on how metalanguage was used as a mediating tool by the learners in understanding targeted grammatical concepts. The protocols of learners' verbalisation during a CBI language task were analysed by Languaging Units identification. Results revealed that the significant role of metalanguage to serve as a communicative tool as well as a psychological tool to support learners' cognitive and linguistic development in their L2 learning.

Dynamic Assessment (DA), raised by Vygotsky, is a kind of interactive assessment used in education, which attempts to diagnose abilities that are fully matured as well as those that are still in the process of maturing. In a "test-teachretest" model, DA emphasizes the individual's ability to acquire knowledge and skills after being exposed to instruction. Ableeva and Lantolf (2011) [25] presented a longitudinal study, highlighting the importance of using DA in promoting listening comprehension in the context of French as a second language. Through analyzing the number of idea units in three aural text genres recalled by learners over time, they found that listening ability improves with an increase in the number of idea units and as a result of mediation. Another study by Davin (2016) [26] also explored the implementation of DA in the foreign language classroom of an elementary school by analyzing the interaction of two learners across both DA and smallgroup work. This paper revealed that the implementation of DA in a SL classroom provided opportunities for the teacher to mediate and help learners to reformulate their utterance.

Jang and DaSilva Iddings (2010) [27] put their experiment in more complex settings. The sources of data were from participant observations, interviews, self-report, informal conversations, student work samples, and other documents. Based on data collected, they mainly made a microgenetic analysis of two immigrant Korean learners' interactions in classroom practices, including The News Reporter (a collaborative task), The Debate, other independent writing and editing tasks, to explore the dynamic process of selfregulation. They found that the activation or development of self-regulation was tightly intertwined with community activities, social and cultural contextual factors in the English-dominated classrooms, and newly formed semiotic resources. SL learning is a goal-directed activity which needs a high degree of self-regulation being activated or developed through internalizing signs in a dynamic context and forming hybrid sign systems.

Apart from language tools, non-verbal activities including gesture also play important roles in SL teaching and learning. Recent decades have witnessed an increasing number of studies highlighting the roles of gesture in SLA, but there is still a need for empirical work that explores how teachers and students employ gesture in SL classroom interactions. McCafferty (2002) [28] examined the interaction from a Taiwanese learner of English and a native English speaker to investigate the role of gestures itself and how it is linked to speech in creating ZPD for second language learning and teaching. Findings indicated that gestures and other body activities contribute to facilitating language learning and positive interaction between interlocutors. A recent study by Matsumoto and Dobs (2016) [29] investigated the functions of gesture in SL grammar learning, like English tense and aspect. They made a micro-analysis of interactions in a beginner-level and an advanced-level grammar classroom and found that gesture, as a crucial element of interactional competence, can be employed by teachers to make abstract concepts concrete and visible to learners and learners can use them to display their L2 grammatical development and construct an interactional relationship with their teachers in the ESL classroom.

Adopting a Dynamic Systems Theory (DST) framework, Verspoor and Van Dijk (2008) [30] was the only one combined DST and microgenetic analysis. This case study analyzed 18 compositions of an advanced learner (Dutch native speaker) majoring in English during the three consecutive years. After analyzing the emergency of complexity in vocabulary and grammar, they found that although a general increase over time is apparent, the development is nonlinear showing moments of progress and regress, and complex with dynamic interaction of subsystems.

\subsection{Current Progress of Domestic Research}

At the beginning of the 21st century, Wen Qiufang (2003) [31] introduced the microgenetic method to Chinese researchers, pointing out the bright application prospects of this method in SLA. Related research based on this method mainly focuses on the frequency effects on second language acquisition, including error correction, vocabulary acquisition, and second language oral abilities. The effect of frequency has been a hot topic in second language research, emphasizing the effect of repetitive practice on the process and results of second language acquisition. Usually, in a short period of time (from a few hours to a few days to a few weeks), the subjects are asked to make repetitive attempts to complete a learning task. Through high-frequency recording and observation of the changes brought about by each repetition, researchers can describe the path, rate and breadth of changes in detail, discover variability and causes led to these changes, and reveal the rules and characteristics of changes and development. 
The error correction researches mainly focus on a certain common pronounce or grammar error. As for pronounce error correction research, Xie Mi (2009) [32] investigated the effect of the practice frequency on the correction of two subjects' $[\mathrm{v}] /[\mathrm{w}]$ confusion errors from the path, speed, breadth, sources of change and variability. The results show that input frequency and output frequency both play an important role in error correction, and the effect of input frequency is more obvious. Liu Feng, Wang Dingming (2013) [33] investigated the effects of practice frequency on the correction of two subjects' $[1] /[\mathrm{n}]$ confusion errors. The results showed that the effect of frequency on the $[1] /[n]$ error correction goes through four stages: "progressretrogress-progress-basic stability". As for grammatical error correction, Li Yuping and Han Lina (2010) [34] examined the efficacy of visualization in modifying the third-person pronouns errors in Chinese EFL learners' oral production. The findings showed that visualization plays a positive role in diminishing the frequency of fossilized error of the third-person pronouns.

Related research also concerns the effect of frequency, including input frequency, out frequency and input interval, on learners' second language vocabulary acquisition and oral abilities. Based on the vocabulary knowledge 5 scales, Cui Jingjing and Liu Zhenqian (2016) [35] analyzed the influence of input interval and input frequency on vocabulary acquisition. The research found that the input interval is not conducive to the vocabulary acquisition if it is too long or too short and the increase of the input frequency is conducive to vocabulary acquisition and maintenance of long-term memory. Oral abilities also have been attached much importance by second language researchers. Zhou Dandan (2004) [36] investigated the effects of task frequency on story retelling. This experiment recorded and analyzed a college student's oral story retelling for 3 consecutive days. The subject listened to the recording twice each day and then retold the story twice. By analyzing the ongoing changes in the repeated tasks, they found that task frequency plays a multidimensional and complex role in oral performance. Zhou Weijing (2005) [37] explored the different effects of visual input frequency and auditory input frequency on oral English production. The results indicated that auditory input has a positive impact on oral fluency, while visual input has a greater effect on the accuracy and complexity of spoken English, and both input and output frequency play important roles in improving the quality of oral production.

\section{CONCLUSION}

Compared with other research methods, microgenetic method can capture ongoing changes in development during a relatively short time period, through dense observation and under in-depth analysis. Given the abundant and high-quality data that this method yields and versatile statistical tools for analysis, it is reasonable to envisage a future in which microgenetic studies have proliferated in the field of SLA. Although this method has shown good adaptability in SLA researches, according to the current research situation, it has not attracted widespread attention from second language researchers, and the research scope is still limited. Current articles mainly focus on the effects of several strategies on second language acquisition, such as gestures, DA, peer revision, frequency effects and so on. Only Verspoor and Van Dijk (2008) [30] was under the DST framework to study the emergency of complexity in learner language. There are still some research gaps, such as the process of acquiring a word family, a given sentence or a lexical chunk, which are worthy of further investigation. Moreover, many researchers pointed out the potential adaptability of mirogenetic method in DST research. One of the challenges of working on SLA is to capture the ongoing emergence of complexity, fluency, and accuracy in learner language (Larsen-Freeman, 2006) [1]. Obviously, highfrequency observation and sampling required by microgenetic method can directly capture ongoing changes in learner language on a lexical as well as syntactic level. In brief, the microgenetic method is a viable tool for investigating SLA-related phenomena for L2 researchers and practitioners. There is still great room for microgenetic studies in the future, not only in terms of theoretical development, but also in terms of empirical employment.

\section{REFERENCES}

[1] D. Larsen-Freeman, "The emergence of complexity, fluency, and accuracy in the oral and written production of five Chinese learners of English", Applied Linguistics, vol. 27, no. 4, pp. 590-619, 2006. DOI: https://doi.org/10.1093/applin/aml029

[2] N. Granott and J. Parziale, Microdevelopment: Transition processes in development and learning. Cambridge: Cambridge University Press, 2002, pp.131156.DOI: https://doi.org/10.1017/CBO9780511489709. 001

[3] R. Siegler, Microgenetic studies of learning. In D. Kuhn \& R. Siegler (Eds.), Handbook Of Child Psychology, 6th ed., vol.2. Hoboken: John Wiley \& Sons, 2007, pp.1-2. DOI: https://doi.org/10.1002/9780470147658.chpsy0211

[4] R. Siegler and K. Crowley, "The microgenetic method: A direct means for studying cognitive development.", American Psychologist, vol. 46, no. 6, pp. 606-620, 1991. DOI: https://doi.org/10.1037/0003$066 x .46 .6 .606$

[5] L. Schauble, "The development of scientific reasoning in knowledge-rich contexts.", Developmental Psychology, vol. 32, no. 1, pp. 102-119, 1996. DOI: https://doi.org/10.1037/0012-1649.32.1.102 
[6] D. Bjorklund, T. Coyle and J. Gaultney, "Developmental differences in the acquisition and maintenance of an organizational strategy: Evidence for the utilization deficiency hypothesis", Journal of Experimental Child Psychology, vol. 54, no. 3, pp. 434448, 1992. DOI: https://doi.org/10.1016/00220965(92)90029-6.

[7] P. Miller and P. Aloise-young, "Preschoolers' strategic behavior and performance on a Same-Different task", Journal of Experimental Child Psychology, vol. 60 , no. 2, pp. 284-303, 1996. DOI: https://doi.org/10.1006/jecp.1995.1042.

[8] H. Werner, "Musical "Micro-scales" and "Micromelodies"", The Journal of Psychology, vol. 10, no. 1, pp. 149-156, 1940. DOI:

https://doi.org/10.1080/00223980.1940.9916990

[9] L. Vygotskij and M. Cole, Mind in society: The development of higher psychological processes. Cambridge, Mass: Harvard Univ. Press, 1978. DOI: http://doi.org/10.2307/j.ctvjf9vz4

[10] R. Siegler, Emerging Minds: The Process Of Change In Children's Thinking. Oxford: Oxford University Press, 1996. DOI: http://doi.org/10.1093/oso/9780195077872.001.0001

[11] R. Siegler, Microgenetic studies of self explanation. In N. Granott \& I. Parziale (eds.). Microdevelopment: Transition Processes in Development und Leaming. Cambridge: Cambridge University Press, 2002, pp.31-58.

DOI: https://doi.org/10.1017/CBO9780511489709.001

[12] R. Siegler, "The rebirth of children's learning", Child Development, vol. 71, no. 1, pp. 26-35, 2000. DOI: https://doi.org/10.1111/1467-8624.00115

[13] Miller P.H. \& T.R. Coyle, Developmental change: Lessons from microgenesis. In E.K. Scholnick, K. Nelson, S.A. Gelman \& P.H. Miller (eds.). Conceptual Development: Piaget's Legacy, 1st ed., vol.2. Psychology Press, 1999, pp.1-2. DOI: http://doi.org/10.4324/9781410603883

[14] R. Siegler, "How does change occur: A microgenetic study of number conservation", Cognitive Psychology, vol. 28, no. 3, pp. 225-273, 1995. DOI: https://doi.org/10.1006/cogp.1995.1006

[15] R. Siegler and E. Stern, "Conscious and unconscious strategy discoveries: A microgenetic analysis.", Journal of Experimental Psychology: General, vol. 127 , no. 4 , pp. $377-397,1998$. DOI: https://doi.org/10.1037/0096-3445.127.4.377

[16] M. De Guerrero and O. Villamil, "Activating the ZPD: Mutual scaffolding in L2 peer revision", The Modern Language Journal, vol. 84, no. 1, pp. 51-68, 2002. DOI: https://doi.org/10.1111/0026-7902.00052

[17] E. Platt and F. Brooks, "Task engagement: A turning point in foreign language development", Language Learning, vol. 52, no. 2, pp. 365-400, 2002. DOI: https://doi.org/10.1111/0023-8333.00187

[18] J. Belz and C. Kinginger, "Discourse options and the development of pragmatic competence by classroom learners of German: The case of address forms", Language Learning, vol. 53, no. 4, pp. 591-647, 2003. DOI: https://doi.org/10.1046/j.1467-9922.2003.00238.x

[19] I. Knouzi, M. Swain, S. Lapkin and L. Brooks, "Self-scaffolding mediated by languaging: microgenetic analysis of high and low performers", International Journal of Applied Linguistics, vol. 20, no. 1, pp. 23-49, 2010. DOI: https://doi.org/10.1111/j.1473-

4192.2009.00227.x

[20] F. DiCamilla and M. Antón, "Functions of L1 in the collaborative interaction of beginning and advanced second language learners", International Journal of Applied Linguistics, vol. 22, no. 2, pp. 160-188, 2012. DOI: https://doi.org/10.1111/j.1473-4192.2011.00302.x

[21] A. Mirzaei and Z. Eslami, "ZPD-activated languaging and collaborative L2 writing", Educational Psychology, vol. 35, no. 1, pp. 5-25, 2013. DOI: https://doi.org/10.1080/01443410.2013.814198

[22] D. Kim and J. Hall, "The role of an interactive book reading program in the development of second language pragmatic competence", The Modern Language Journal, vol. 86, no. 3, pp. 332-348, 2002. DOI: https://doi.org/10.1111/1540-4781.00153

[23] R. van Compernolle, "Developing second language sociopragmatic knowledge through concept-based instruction: A microgenetic case study", Journal of Pragmatics, vol. 43, no. 13, pp. 3267-3283, 2011. DOI: https://doi.org/10.1016/j.pragma.2011.06.009

[24] H. Harun, N. Abdullah, N. Ab. Wahab and N. Zainuddin, "The use of metalanguage among second language learners to mediate L2 grammar learning", Malaysian Journal of Learning and Instruction, vol. 14, no. 2 , pp. $85-114$, 2017. DOI:

https://doi.org/10.32890/mjli2017.14.2.4 
[25] R. Ableeva and J. Lantolf, "Mediated dialogue and the microgenesis of second language listening comprehension", Assessment in Education: Principles, Policy \& Practice, vol. 18, no. 2, pp. 133-149, 2011. DOI: https://doi.org/10.1080/0969594x.2011.555330

[26] K. DAVIN, "Classroom dynamic assessment: A critical examination of constructs and practices", The Modern Language Journal, vol. 100, no. 4, pp. 813-829, 2016. DOI: https://doi.org/10.1111/modl.12352

[27] E. Jang and A. DaSilva Iddings, "The social genesis of Self-Regulation: The case of two Korean adolescents learning English as a second language", Mind, Culture, and Activity, vol. 17, no. 4, pp. 350-366, 2010. DOI:

https://doi.org/10.1080/10749030903362707

[28] S. McCafferty, "Gesture and creating zones of proximal development for second language learning", The Modern Language Journal, vol. 86, no. 2, pp. 192203, 2002. DOI: https://doi.org/10.1111/15404781.00144

[29] Y. Matsumoto and A. Dobs, "Pedagogical gestures as interactional resources for teaching and learning tense and aspect in the ESL grammar classroom", Language Learning, vol. 67, no. 1, pp. 7-42, 2016. DOI: https://doi.org/10.1111/lang.12181

[30] M. Verspoor, W. Lowie and M. Van Dijk, "Variability in second language development from a dynamic systems perspective", The Modern Language Journal, vol. 92, no. 2, pp. 214-231, 2008. DOI: https://doi.org/10.1111/j.1540-4781.2008.00715.x

[31] Wen Qiufeng, "The microgenetic method and second language acquisition research", Modern Foreign Language, no. 3, pp. 312-317+311, 2003. (In Chinese) DOI: https://doi.org/CNKI:SUN:XDWY.0.2003-03-012

[32] Xie Mi, "A microgenetic study of the frequency effects on $[\mathrm{v}] /[\mathrm{w}]$ confusion correction"(in Chinese),
Foreign Languages Research, no. 1, pp. 63-69, 2009. (In Chinese) DOI:

https://doi.org/CNKI:SUN:NWYJ.0.2009-01-014

[33] Liu Feng, Wang Dingming, Gao Huaiyong and Ji Huanqi, "The effect of frequency on $[1] /[n]$ confusion correction", Journal of PLA University of Foreign Languages, vol. 36, no. 5, pp. 59-63, 2013. (In Chinese) DOI: https://doi.org/CNKI:SUN:JFJW.0.2013-05-012

[34] Li Yuping and Han Lina, "Catalytic effect of Visualization-Exemplified by its effect on modifying error of Third-Person Pronouns in Chinese EFL learners' oral output", Journal of Tianjin University (Social Sciences), vol. 12, no. 5, pp. 477-480, 2010. (In Chinese) DOI:

https://doi.org/CNKI:SUN:TDXS.0.2010-05-020

[35] Cui Jingjing and Liu Zhenqian, "A microgenetic study of the effects of input interval and input frequency on L2 vocabulary acquisition", Journal of Xi'an International Studies University, vol. 24, no. 2, pp. 5661, 2016. (In Chinese) DOI:

https://doi.org/10.16362/j.cnki.cn611457/h.2016.02.013

[36] Zhou Dandan, "Effects of task frequency on story retelling", Journal of PLA University of Foreign Languages, no. 5, pp. 41-45, 2004. (In Chinese) DOI: https://doi.org/CNKI:SUN:JFJW.0.2004-05-010

[37] Zhou Weijing, "Effects of input modes on oral English production", Journal of PLA University of Foreign Languages, no. 6, pp. 57-62, 2005. (In Chinese) DOI: https://doi.org/CNKI:SUN:JFJW.0.2005-06-010 